\title{
Space Closure Rate in Mandibular Canine Retraction by Elastomeric Power Chain: A Clinical Trial
}

Md. Kamrul Hasan ${ }^{1 *}$

Gazi Shamim Hassan ${ }^{2}$

Samira Rahman ${ }^{3}$

Sher $\mathrm{Ali}^{4}$

Md. Azizur Rahman ${ }^{5}$

Mahfuj Hasan ${ }^{6}$

Rokeya Rahman Tani ${ }^{7}$

'Department of Orthodontics Chattagram International Dental College Chattogram, Bangladesh.

${ }^{2}$ Department of Orthodontics and Dean Faculty of Dentistry, BSMMU

Dhaka, Bangladesh.

${ }^{3}$ Department of Radiology and Imaging Chattagram Maa-O-Sishu Hospital

Chaattogram, Bangladesh.

${ }^{4}$ Department of Orthodontics Khulna Medical College Khulna, Bangladesh.

${ }^{5}$ Department of Orthodonties

Ibn Sina Diagnostic and Consultation Center Dhaka, Bangladesh.

${ }^{6}$ Department of Orthodontics

Shaheed Suhrawardy Medical College

Dhaka, Bangladesh.

${ }^{7}$ Department of Dentistry

Dhaka Medical College

Dhaka, Bangladesh.

*Correspondence to:

Dr. Md. Kamrul Hasan

Assistant Professor

Department of Orthodontics

Chattagram International Dental College

Chattogram, Bangladesh.

Mobile : +88 01712513431

Email :dr.kamrul_cmc@yahoo.com

Date of Submission : 25.05 .2021

Date of Acceptance ～: 20.06 .2021

www.banglajol.info/index.php/CMOSHMC

\begin{abstract}
Background : On a daily basis, orthodontic patients present with malocclusions and orofacial imbalance. Often times, teeth must be extracted in order to obtain proper esthetics, occlusion, and stability as well as extraction of teeth is often a need to close residual space, after the initial decrowding and aligning. Pre adjusted fixed orthodontic appliances commonly utilize sliding mechanics for space closure with different types of force delivery systems. A variety of materials have been used as force delivery systems to close spaces between teeth as in the case of canine retraction after the extraction of premolars. Elastomeric auxiliaries are relatively consistent in producing tooth movements. The purpose of the study to evaluate the rate of mandibular canine retraction by elastomeric power chain.
\end{abstract}

Materials and methods : This obervational study was designed as split mouth study. A total number of 20 patients (40 quadrants), who required canine retraction into first premolar extraction sites as part of their orthodontic treatment in the Department of Orthodontics, BSMMU as study population. The quadrants were affixed by elastomeric power chain (Dentaurum) with $200 \mathrm{gm}$ force measured by Correx Tension Gauge. Space closure was measured by means of direct measurement from the mesial surface of mesial wing of the 2nd premolar bracket and the distal surface of distal wing of the canine bracket with digital Vernier Calipers.

Results: Mean space closer rate in mandibular canine retraction was $0.99 \pm 0.08$ $\mathrm{mm} /$ month in elastomeric power chain method with $p$ value $<0.001$.

Conclusion : This study revealed that space closer rate in mandibular canine retraction was $0.99 \pm 0.08 \mathrm{~mm} /$ month by elastomeric power chain.

Key words : Canine retraction; Elastomeric Power Chain; Orthodontic patient.

\section{INTRODUCTION}

On a daily basis, orthodontic patients present with malocclusions and or facial imbalance. Often times, teeth must be extracted in order to obtain proper esthetics, occlusion, and stability. Extraction of teeth can improve the facial esthetics of a patient with procumbent or protrusive lips. This can be accomplished by retracting the anterior teeth into the extraction spaces, thus retracting the lips to a more balanced position ${ }^{1-3}$. Tweed's work revolutionized the field in the1940's and 1950's as it now became acceptable to extract teeth for orthodontic correction. In 1989, a survey of 238 orthodontists in Michigan was conducted to evaluate the prevalence of orthodontic extractions and found the mean rate of extraction treatment to be $39 \%$. The rate of extraction varied greatly between orthodontists ${ }^{4}$. In severe crowding and extraction cases, the canines have been distalized to relive the crowding as space to correctly align the incisors will not be available. Canine retraction is a very important 
step in treatment of patients with crowding needed first premolar extraction. Orthodontic treatment involving extraction of teeth is often a need to close residual space, after the initial decrowding and aligning ${ }^{5-7}$. The closure of space can be achieved by two techniques, friction (Sliding) mechanics or frictionless (Loop) mechanics. Sliding (Frictional) mechanics involves either moving the brackets along the arch wire or sliding the arch wire through bracket \& tube. Loop (Frictionless) mechanics involves movement of teeth without the brackets sliding along the arch wire but with the help of loops ${ }^{8-10}$. Pre adjusted fixed orthodontic appliances commonly utilize sliding mechanics for space closure with different types of force delivery systems ${ }^{11-16}$. A variety of materials have been used as force delivery systems to close spaces between teeth as in the case of canine retraction after the extraction of premolars. These include latex elastics, coil spring, elastic module, elastomeric power chain, headgear and magnet ${ }^{12,13}$. Elastomeric auxiliaries are relatively consistent in producing tooth movements ${ }^{5,18}$. The most time consuming stage of premolar extraction based orthodontic treatment is canine retraction. Any procedure which reduces the time required to retract canine will also serve to shorten overall treatment time. Reducing the duration of orthodontic treatment is of great interest to orthodontists ${ }^{16-18}$. In context of Bangladesh, there is no study regarding space closure rate in canine retraction by any force system.

The purpose of the study to evaluate the rate of mandibular canine retraction by elastomeric power chain.

\section{MATERIALS AND METHOD}

This observational study was designed as split mouth study. A total number of 20 patients (40 quadrants), who required canine retraction into first premolar extraction sites as part of their orthodontic treatment in the Department of Orthodontics, Bangabandhu Sheikh Mujib Medical University (BSMMU) as study population. Study period was from May 2015 to April 2016. Patients were selected by following criteria.

\section{Inclusion criteria}

i) Age between 15 to 30 years

ii) Who gave consent for inclusion in the study

iii) Patients of any sex

iv) 1 st premolar extraction case.

\section{Exclusion criteria}

i) Age more than 30 years

ii) 2nd premolar extraction case

iii) Missing or extracted first molar

iv) Mesial drifting of first molar.

All the patients were treated with pre adjusted edge-wise fixed appliance using stainless steel $0.018 \times 0.025$ inch slot Roth brackets. After all first premolars were extracted, initial leveling and alignment was carried out. All teeth were ligated with 0.010 stainless steel litgature wire. Standardized anchorage control using tip back and toe in bend was used in all patients and $2^{\text {nd }}$ premolars were included in anchorage unite. Then canine retraction carried out by individual sliding of canine using round 0.016 inch stainless steel arch wire with elastomeric Power Chain. The quadrants were affixed by elastomeric Power Chain (Dentaurum) with 200gm force measured by Correx Tension Gauge. Space closure was measured by means of direct measurement from the mesial surface of mesial wing of the 2 nd premolar bracket and the distal surface of distal wing of the canine bracket with digital Vernier Calipers.

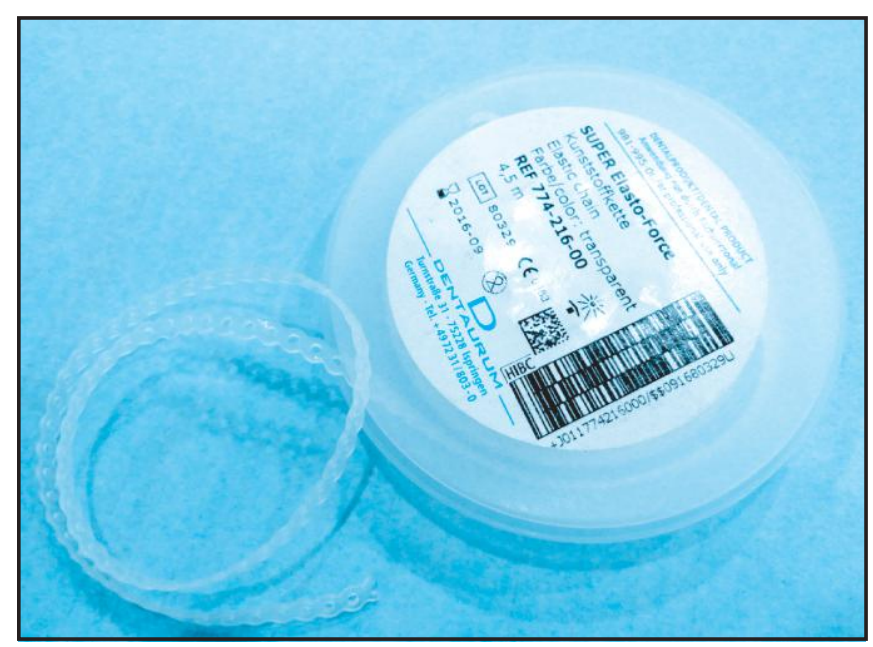

Figure 1 : Elastomeric power chain

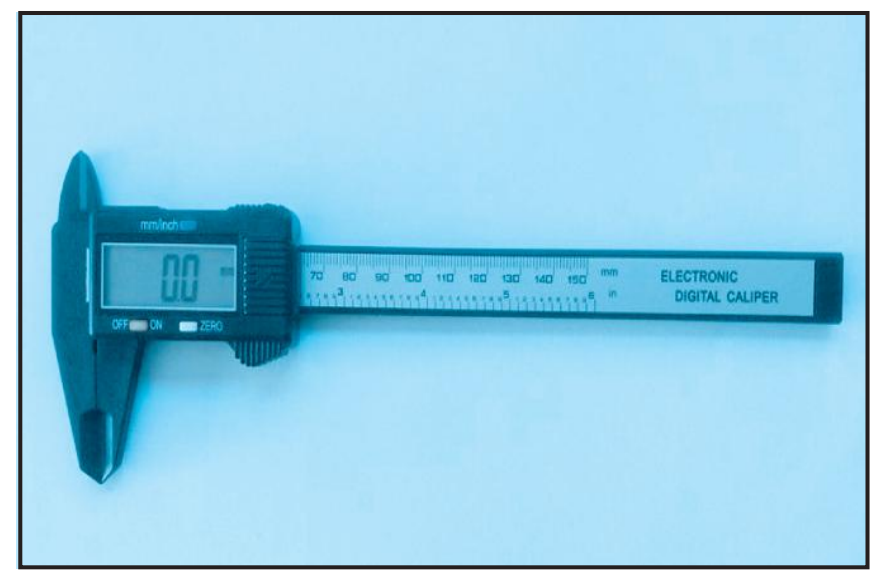

Figure 2 : Digital vernier calipers

\section{RESULTS}

During this study period distribution of patients according to gender, Female were predominant. Male female ratio was 1:4. Amongst the patients, Maximum $11(55.0 \%)$ were in age group 16-20 years followed by 7 (35.0\%) and 2 (10.0\%) were in age group 21-25 years and $>25$ years age group respectively. Mean of age was $20.60 \pm 3.54$ years within the range of 16-27 years. 


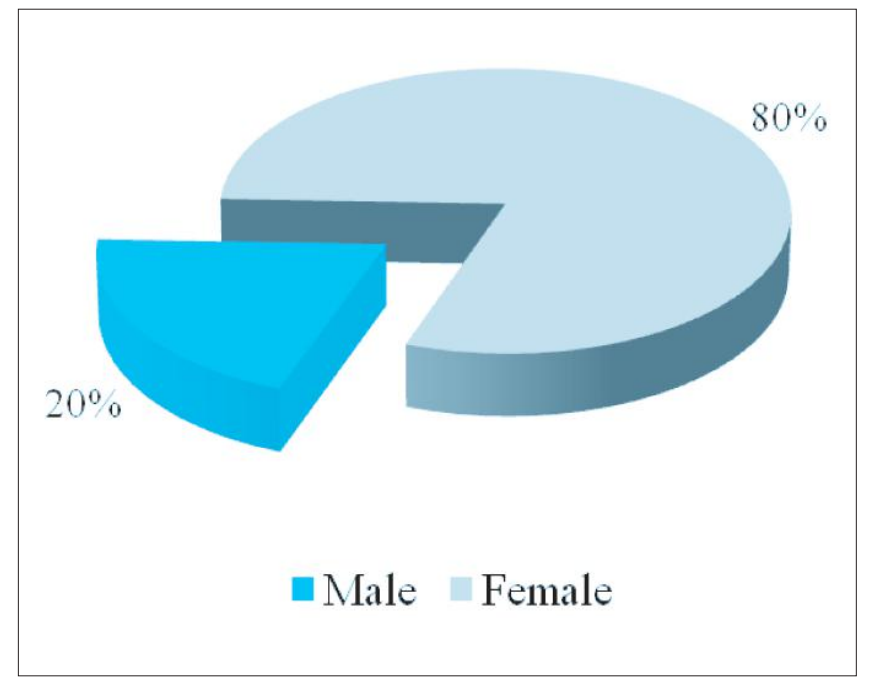

Figure 3 : Pie chart of patients according to gender

Figure 3 shows distribution of patients according to gender. Female were predominant. Male female ratio was 1:4.

Table I : Distribution of patients according to age

\begin{tabular}{lrr} 
Age & Frequency & Percentage \\
$16-20$ & 11 & 55.0 \\
$21-25$ & 7 & 35.0 \\
$>25$ & 2 & 10.0 \\
Total & 20 & 100.0 \\
Mean \pm SD & $20.60 \pm 3.54$ & \\
Range (Min - Max) & $16-27$ & \\
\hline
\end{tabular}

Table I shows distribution of patients according to age. Maximum 11 (55.0\%) were in age group 16-20 years followed by $7(35.0 \%)$ and $2(10.0 \%)$ were in age group $21-25$ years and $>25$ years age group respectively. Mean of age was $20.60 \pm$ 3.54 years within the range of 16-27 years.

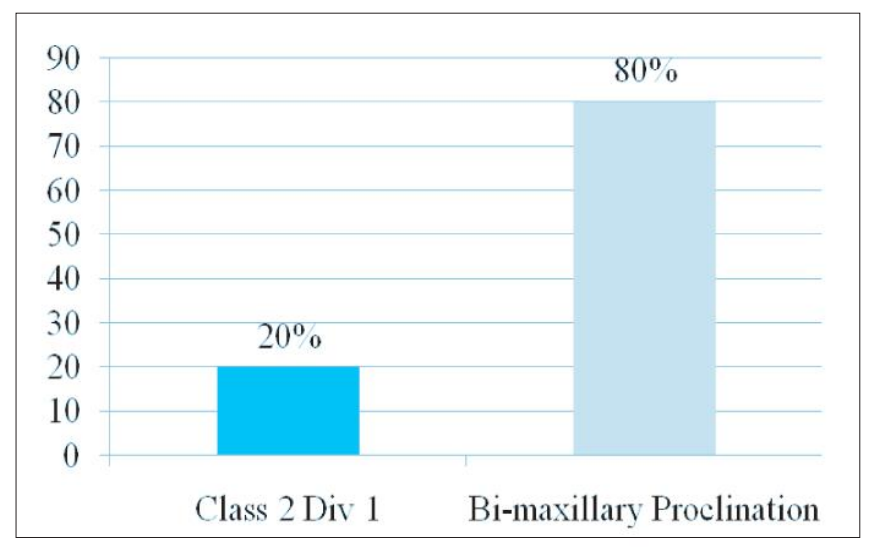

Figure 4 : Bar diagram Distribution of patients according to type of occlusion
Figure 4 shows distribution of patients according to type of occlusion. Maximum $16(80.0 \%)$ cases were Bi-maxillary proclination and $4(20.0 \%)$ cases were Class 2 div 1 .

\section{DISCUSSION}

Over the period of one year from May 2015 to April 2016, this clinical trial was carried out in the Department of Orthodontics at Bangabandhu Sheikh Mujib Medical University (BSMMU). A total of twenty patients were selected for canine retraction. Among all patients female were predominant with male and female ratio 1:4. According to age distribution, mean age was measured $20.60 \pm 3.54$ years within the range of 16-27 years. Maximum patients were in age group 16-20 years which accounted $55.0 \%$ that followed by $35.0 \%$ and $10.0 \%$ were in age group 21-25 years and $>25$ years age group respectively. Young populations especially female are more inclined to get a better aesthetic configuration of own self. This may be one of the causes of such type of age and sex distribution in our study. Among 17 patients in a study done by Samuels, Rudge, and Mair, there were 12 girls and 5 boys with a mean age of 14.7 years $(\text { Range }=11.1 \text { to } 17.1 \text { years })^{13}$.

In this study, a majority of $80.0 \%$ cases were Bi-maxillary proclination and the rest of $20.0 \%$ cases were Class 2 div 1.Mean space closer rate was $0.95 \pm 0.06 \mathrm{~mm} / \mathrm{month}$ in male and $1.02 \pm 0.10 \mathrm{~mm} /$ month in female in elastomeric power chain method in mandible. There was no statistical significant difference between these two groups. Unpaired t test was done to measure the level of significance.

In consideration of total time required for closing the space in canine retraction (Months) Mean time to closing the space was $6.45 \pm 0.83$ months in elastomeric power chain method in mandible.

A clinical trial done in England on twenty seven patients and found $0.27 \mathrm{~mm} /$ week mean rate of tooth movement in conventional elastic ${ }^{14,12}$.

In our study mean space closer rate in mandibular canine retraction is $0.99 \pm 0.08 \mathrm{~mm} / \mathrm{month}$ in elastomeric power chain method with $\mathrm{p}$ value $<0.001$.

\section{CONCLUSION}

This study revealed that space closer rate in mandibular canine retraction is $0.99 \pm 0.08 \mathrm{~mm} / \mathrm{month}$ by elastomeric power chain method.

\section{DISCLOSURE}

All the authors declared no competing interest. 


\section{REFERENCES}

1. Proffit, W.R., Fields, H.W., Sarver, D.M. Contemporary Orthodontics. $5^{\text {th }}$ edn St. Louis, MO: Elsevier/Mosby. 2001.

2. Proffit, W.R. Contemporary orthodontics. 1992: $2^{\text {nd }}$ edn: Mosby, St Louis. 1992.

3. Samuels, R.H., Rudge, S.J, and Mair, L.H.A. Comparison of the space closure using a nickel titanium spring and an elastic module: a clinical study. Am J Ortho DentofacialOrthop. 1993: 106(5):464 - 467.

4. Weintraub, J.A., Vig, P.S., Brown, C., Kowalski, C.J. The prevalence of orthodontic extractions. Am J OrthodDentofacialOrthop. 1989: 96(6): $462-466$.

5. Dixon, V., Read, M.J.F., O'Brien, K.D. Worthington HV and Mandall NA. A randomized clinical trial to compare three methods of orthodontic space closure, J Orthod. 2002: 29(1): 31-36.

6. Graber, T.M., Vanarsdall, R.L., Vig, K.W.L. Orthodontics: Current Princples and Techniques. St. Louis, MO: Elsevier Mosby. 2005.

7. McLaughlin, R.P., Bennett, J.C., Travesi, H.J. Systematized orthodontic treatment mechanics. Edinburgh: Mosby. 2007.

8. Chimenti, C., Lecce, D., Santucci, L., Parziale, V, and Lucci, M. In vitro assessment of elastomeric of elastomeric chain behavior. ProgOrthod. 2001: 2(1): 42.

9. Eliades, T., Gioka, C., Zineus, S, and Makoy, M. Study of stress relaxation of orthodontic elastomers. pilot method report with continuous data collection in real time. Hel Orthod Rev. 2003: 6: 13-26.

10. Kanuru, R.K., Azaneen, M., Narayana, V., Kolasani, B., Indukuri, R.R., Babu, F.P. Comparison of canine retraction by in vivo method using four brands of elastomeric power chain. J IntSoc Prevent Communit Dent. 2014: 4: S32-S37.

11. Sowmya, K.S., Chandralekha, B., Uma, H.L., Kumari, S.V., Padmini, M.N. Comparison of Active Tie Backs and Nickel Titanium Coil Springs in Canine Retraction: A Clinical Study with the MBT System. The Orthodontic Cyber Journal. 2011.

12. Sonis, A.L. Comparison of NiTi coil springs vs. elastics in canine retraction. J ClinOrthod, 1994: 28(5): 293-295.

13. Samuels, R.H.A., Rudg, S.J., Mair, L.H. Study of space closure with nickel titanium closed coil spring and an elastic module. Am J orthod. 1998: 114: 73-79.

14. Sonis, A.L., Van der Plas, E. and Gianelly, A. A comparison of elastomeric auxiliaries versus elastic thread on premolar extraction site closure: An in vivo study. American journal of orthodontics. 1986: 89(1): 73-78.

15. Miura, F., Mogi, M., Ohura, Y. and Karibe, M. The super-elastic Japanese NiTi alloy wire for use in orthodontics part III. Studies on the Japanese NiTi alloy coil springs. American Journal of Orthodontics and Dentofacial Orthopedics. 1988: 94(2): 89-96.

16. Eberting, J.J., Straja, S.R., Tuncay, O.C. Treatment time, outcome and patient satisfaction comparisons of Damon and conventional brackets. ClinOrthod Res. 2001: 4: 228-234.

17. Al-Sayagh, N.M., Ismael, A.J. 'Evaluation of space closure rate during canine retraction with nickel titanium closed coil spring and elastomeric chain. Al-Rafidain Dent J. 2011: 11(1): 146-153.

18. Kulshrestha, R.S., Tandon, R., Chandra, P. Canine retraction: A systematic review of different methods used, Journal of Orthodontic Science. 2015: 4(1): 1-8. 